\title{
IRAJETÓRIAS DE UMA ANTROPOLOGIA DA SAUDADE: ENTREVISTA COM BELA FELDMAN-BIANCO
}

Beatriz Ribeiro Machado*

Universidade Federal de Viçosa - Brasil

Leonardo Vilaça Dupin**

Universidade Estadual de Campinas - Brasil

Victor Cezar de Sousa Vitor ${ }^{* * *}$

Universidade de Brasília - Brasil

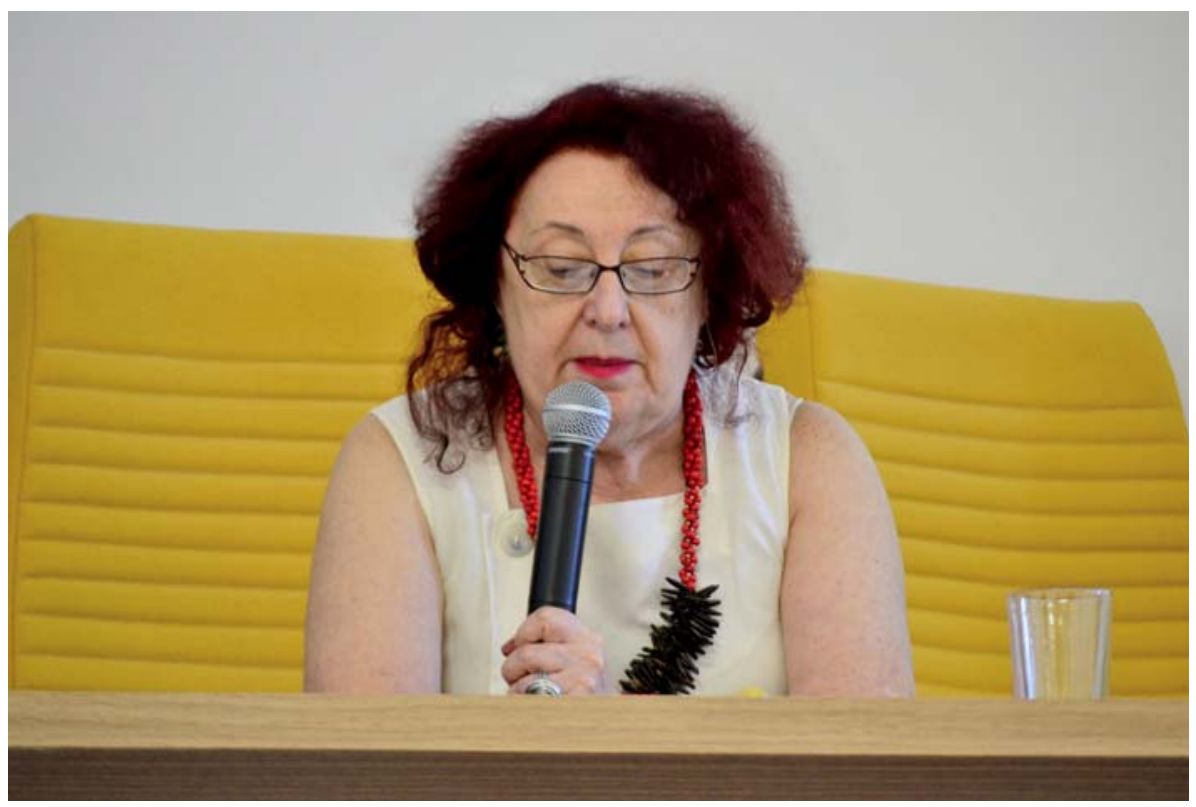

Bela Feldman-Bianco (foto: Fábio Durso).

* Mestranda em Extensão Rural. Contato: beatrizribeiro.ufv@gmail.com

** Doutorando em Ciências Sociais. Contato: leodupin@hotmail.com

*** Mestrando em Antropologia Social (bolsista CNPq). Contato: v2.cis.10@gmail.com

Horizontes Antropológicos, Porto Alegre, ano 23, n. 48, p. 337-350, maio/ago. 2017

http://dx.doi.org/10.1590/S0104-71832017000200014 
Entrevistar Bela Feldman-Bianco é uma tarefa no mínimo honrosa e instigante. As contribuições de Feldman-Bianco dentro da antropologia brasileira já datam de mais de três décadas. Ela é uma das mais importantes autoras nas pesquisas em antropologia política no Brasil, tendo presidido Associação Brasileira de Antropologia (ABA) nos anos 2011-2012. Em 27 de abril de 2016, conversamos com ela durante um seminário sobre ensino e pesquisa da antropologia $^{1}$ na Universidade Federal de Viçosa (UFV), do qual participou junto a outros grandes nomes da antropologia, que foram por nós definidos como "nossos livros vivos".

Feldman-Bianco tem interesse por temas como globalização, migrações e deslocamentos, reconstrução de nação, colonialismo/pós-colonialismo, memória e identidades, a partir de um foco em cultura e poder. Como discorre na entrevista, de um engajamento político que a levou por interessar-se em "fazer reforma agrária" e "fugir" da temática indígena, acabou encontrando e se encontrando na pesquisa sobre temáticas relacionadas à migração e construção social da saudade. Contingencialmente, anos mais tarde, depois de passar por instituições como Coordenação de Aperfeiçoamento de Pessoal de Nível Superior (Capes) e ABA, os deslocamentos compulsórios de Belo Monte colocaram novamente a questão indígena em seu caminho, que a estimularam a desenvolver uma perspectiva global das migrações e deslocamentos.

Em sua trajetória, Feldman-Bianco graduou-se em Ciências Sociais na USP, tornou-se mestre e doutora em Antropologia pela Universidade de Columbia e ainda realizou pós-doutorado em História por Yale, nos EUA. Ocupou, entre 1987 e 1991, a cátedra de Professor Titular em Estudos Portugueses na Universidade de Massachusetts Dartmouth e, em 2008, a cátedra Hélio e Amélia Pedrosa junto ao Center for Portuguese Studies and Culture e ao Departamento de Sociologia dessa mesma universidade. Mais recentemente, no segundo semestre de 2015, ocupou a cátedra Unesco/

\footnotetext{
O evento "O ensino e a pesquisa de antropologia na Mata mineira" teve como objetivo refletir coletivamente e trocar experiências sobre a formação de antropólogos e a produção de conhecimentos na área, no contexto particular da Zona da Mata mineira, contando com a coordenação do Prof. Douglas Mansur da Silva (UFV), Prof. Guillermo Vega Sanabria (UFV), Profa. Raquel dos Santos Souza Lima (UFV), Profa. Cristina Dias da Silva (UFJF), Prof. Luzimar Paulo Pereira (UFJF) e Prof. Raphael Bispo dos Santos (UFJF), além de palestras e mesas-redondas com a participação da Profa. Rogéria Dutra (UFJF), Profa. Elizabeth Pissolato (UFJF), Prof. Marcelo Camurça (UFJF), Profa. Sheila Maria Doula (UFV), Prof. Marcelo José Oliveira (UFV), Profa. Ana Luisa Borba Gediel (UFV), Prof. Carlos Reyna (UFJF) e Profa. Maria de Fátima Lopes (UFV).
}

Horizontes Antropológicos, Porto Alegre, ano 23, n. 48, p. 337-350, maio/ago. 2017 
Memorial da América Latina, tendo ministrado o curso "Desloca(Migra) mentos mentes". É atualmente professora colaboradora do Programa de PósGraduação em Antropologia Social e diretora-adjunta do Centro de Estudos de Migrações Internacionais (Cemi) na Unicamp e pesquisadora do CNPq, nível 1. Também coordena o Comitê Migrações e Deslocamentos da ABA e representa a Sociedade Brasileira para o Progresso da Ciência (SBPC) no Conselho Nacional de Imigração (CNIg).

Timidamente, durante o coffee break do seminário, encontramos abertura e coragem para nos aproximarmos e propor uma entrevista, e ela prontamente aceitou. Assim, no hall do prédio onde acontecia o evento, nos intervalos que se sucediam, sentados em uma espécie de arquibancada, a entrevista aconteceu de maneira informal, mas com muita solicitude da entrevistada, que pode falar livremente sobre sua trajetória.

Ali, Feldman-Bianco relatou sobre o início de sua vida acadêmica, suas contribuições para a pesquisa antropológica brasileira, assim como sobre suas atividades em instituições como a ABA e a Capes. No texto que se segue, por uma questão didática, dividimos as falas em quatro eixos temáticos. Mais do que um depoimento pessoal, a fala da professora e pesquisadora é um documento sobre suas contribuições para a antropologia brasileira nas últimas décadas.

Agradecemos em especial à professora e pesquisadora Bela FeldmanBianco, que além de nos contemplar com esta entrevista-em tom de conversa-, se dispôs a nos ensinar e contribuir com este trabalho do início ao final de sua execução, através de suas revisões e considerações sobre o texto.

\section{0 início da carreira e o engajamento na antropologia}

Em inícios dos anos 1960, eu me sentia muito dividida entre dois campos. Eu queria ser atriz e cursar a Escola de Arte Dramática! Ao mesmo tempo, queria estudar ciências sociais. Por coincidência, os dois vestibulares foram marcados para as mesmas datas. Tive que escolher! Aparentemente o meu lado político foi mais forte e eu decidi prestar vestibular para as ciências sociais para a alegria da minha mãe que não via com bons olhos o meu interesse pelo teatro! Naquela época, o vestibular da USP era bem diferente. Havia 30 vagas para o período diurno e outras 30 para o noturno. Como eu trabalhava durante o dia, optei pelo curso noturno. Havia 
provas escritas e provas orais, todas eliminatórias! Na última prova oral, fui entrevistada pelo Fernando Henrique Cardoso, que me perguntou por que eu queria fazer ciências sociais. De pronto, respondi: "Porque quero fazer reforma agrária!" Lembro que eu queria muito trabalhar na Sudene [Superintendência do Desenvolvimento do Nordeste] ou no Incra [Instituto Nacional de Colonização e Reforma Agrária]. Nunca aconteceu, até porque houve o golpe de 1964. Mas mostra o meu engajamento político. Primeiro, escolhi sociologia e não antropologia! Eu gostava muito da antropologia, mas, naqueles tempos, a Sociologia I, sob a liderança do mestre Florestan Fernandes, era mais forte. Havia toda uma discussão sobre questões relacionadas a desenvolvimento e subdesenvolvimento que despertavam o meu interesse. Na época, consegui uma bolsa de estudos no âmbito de uma pesquisa sobre padrões de vida da classe operária, coordenada pela Lenina Pomerantz, que era da Faculdade de Economia da USP e, ainda, um emprego de meio-período com o arquiteto Vilanova Artigas, com quem aprendi muito sobre os dilemas da arte e técnica. Mas, depois do golpe de 1964, o Artigas se exilou no Uruguai e a Lenina, que havia ido estudar na União Soviética, não pôde voltar ao Brasil por um bom tempo! Como o meu marido fazia medicina em tempo integral, eu é quem sustentava a casa! Tinha que trabalhar! Consegui um emprego na Lintas Publicidade Internacional em pesquisa qualitativa, especialmente discussões em grupo, os assim chamados focus groups. Essas discussões em grupo forneciam subsídios para campanhas publicitárias, e nos faziam entender os padrões de consumo das donas de casa. Trabalhei, primeiro, com um excelente sociólogo/antropólogo, o Renato Jardim Moreira, que havia sido assistente do Florestan Fernandes antes de se tornar publicitário. Ele era ótimo! Foi com quem aprendi a pensar antropologicamente. Eventualmente o Renato foi trabalhar na Shell e eu fiquei no seu lugar. Mas eu também queria continuar a estudar! Primeiro, devido à influência do Rodolfo Azzi (que também fazia pesquisa qualitativa para a publicidade), pensei em fazer uma especialização em psicologia social. Por isso, me matriculei na Psicologia da USP, mas lá os cursos disponíveis eram na área da psicologia experimental, que não era o que eu estava procurando. E acabei, circunstancialmente, encontrando a antropologia. De alguma forma, a publicidade (que constituía à época um grande mercado de trabalho para cientistas sociais) e o meu interesse em comunicação de massas me levaram à antropologia! 
Mas não foi tão simples. Há que se lembrar que estávamos vivendo num estado ditatorial. E era muito complicado continuar a viver no Brasil. Tivemos a possibilidade de sair do país quando o meu marido recebeu uma proposta para trabalhar com um pesquisador brasileiro na New York University. Fui falar com o mestre Florestan Fernandes, porque queria aproveitar minha estada em New York para voltar a estudar. Tendo em vista a minha experiência em publicidade, disse para ele que queria estudar comunicação de massa! Mas a resposta dele foi um categórico "não!": "Se você for para os Estados Unidos, tem que estudar antropologia." Lembro que reagi, "mas não quero estudar índio!". Daí o Florestan disse: "Mas deixa de ser burra! Antropologia não é só [estudar] índio! [risos]. A nossa sociologia é muito mais próxima à antropologia do que à sociologia americana. Se fizer comunicação de massa, você não vai gostar porque se trata de uma outra sociologia." E ele escreveu uma carta me apresentando para o Charles Wagley, professor de Antropologia da Columbia, que era um brasilianista casado com uma brasileira, Cecília Roxo, e que havia iniciado seus estudos no Brasil com uma pesquisa sobre os Tapirapé e, mais tarde, participado, com seus alunos, do projeto da Unesco sobre a questão racial. Em um de seus livros, An introduction to Brazil, ${ }^{2}$ há um capítulo muito bonito, cujo título traduzido para o português seria "se eu fosse brasileiro", em que apresenta suas sugestões para o Brasil, que ele amava muito. Então, assim que cheguei à New York, fui conversar com o Charles Wagley. Obviamente, entreguei a carta do Florestan dirigida a ele, já adiantando: "Eu quero estudar comunicação de massas!" Ele falou: "Não, mas não! Você tem que estudar antropologia, que é mais próxima da sociologia brasileira!" [risos]. Agradeci e, como sou teimosa, me inscrevi como ouvinte num curso de comunicação de massas da New York University. Mas logo percebi que eles tinham toda a razão porque, naquele curso, comunicação de massas era sinônimo de marketing! Coincidentemente, naquela época, por intermédio da Judith Shapiro, que havia estudado os Yanomami, entrei numa rede social de antropólogos "brasilianistas" da Columbia que estavam em fase de redação de suas teses de doutorado através do quais comecei a me inteirar mas sobre a antropologia norte-americana. Daí voltei a conversar com o Charles Wagley, que sugeriu para eu me candidatar a dois programas de pós-graduação em

2 Ver Wagley (1963). 
antropologia, não só no da Columbia University, mas também no da CUNY [City University of New York]. Fui aprovada em ambos. Eu poderia ter começado a estudar uns seis meses antes se tivesse optado pela CUNY, mas os meus amigos da Columbia disseram: "Não! Tem que esperar porque a Columbia é melhor!" E eu optei por fazer meu mestrado e Ph.D. na Columbia! Mais tarde, o Programa da CUNY se tornou excelente!

Naqueles anos, a conjuntura norte-americana era interessante. Saímos do Brasil após o ato institucional $\mathrm{n}^{\mathrm{o}} 5$, de dezembro de 1968, quando a ditadura militar endureceu e a situação brasileira se tornou dramática. Chegamos em New York no auge dos grandes movimentos sociais, feminismo, Black Power, Young Lords, que era o movimento dos porto-riquenhos. E, naquela época, os Estados Unidos ainda estavam em guerra contra o Vietnã e as manifestações contra a guerra eram contínuas. Os estudantes do programa de pós-graduação em antropologia da Columbia eram muito interessantes e politizados, gente de vários backgrounds, bem diversificada, inclusive da esquerda americana. Éramos contra a guerra do Vietnã, íamos às demonstrações em Washington, participávamos também das manifestações feministas, entrando em contato com feministas de vários matizes. Vivemos os anos Nixon, o Watergate! Conheci os Black Painters e os Young Lords. Fiz pesquisa no Lower Side de Manhattan sobre drogas. E também militava contra a ditadura brasileira junto com exilados e brasilianistas. Foi um período muito intenso e estimulante em várias frentes, me fez pensar muito, abriu a minha cabeça! Liberação feminista, liberação de tudo! Deixei meu marido. Me liberei! Acho que eu já era liberada, mas me liberei mais! Foi durante esse processo que me tornei antropóloga.

\section{Vivências migrantes e interesses de pesquisa}

Migrar é um processo complexo. A minha volta [dos EUA] ao Brasil foi bem complicada! Cheguei na Unicamp depois da minha defesa de tese [na Columbia]. Defendi em fevereiro de 1980 e viajei em seguida para o Brasil, para começar o semestre em março. Depois de sair de São Paulo para viver em Nova York, por uma boa época não pude voltar por motivos políticos! Me senti exilada. Sofria porque eu queria estar no Brasil. E reelaborava o passado brasileiro no cotidiano americano, cozinhando cuscuz, feijoada, ouvindo música brasileira! E, depois, quando voltei ao Brasil, compreendi que realmente 
não se volta. Você volta a um outro lugar, mesmo sendo o mesmo lugar. Você muda, o lugar e as pessoas mudam também e, o pior, algumas nem mudam - mas já não é o mesmo lugar! Você passa por um processo semelhante ao emigrar e chegar a um novo país! Essa experiência pode ser muito sofrida, mas é, ao mesmo tempo, muito rica. Aprende-se muito, inclusive em termos intelectuais! Quando comecei a pós-graduação na Columbia, a minha reação aos diversos cursos que fiz, era: por que é que estão fazendo essas perguntas? Minha postura foi sempre crítica! E quando você volta, é a mesma coisa: novamente você começa a perguntar sobre as perguntas que estão sendo feitas. O grande desafio é entender como o conhecimento está sendo elaborado e a partir de onde está sendo formulado, já que estamos expostos a formas diferentes de produzir conhecimento. Esse processo de perguntar, criticar, repensar e problematizar é extremamente rico. É a forma de descobrirmos os nossos próprios caminhos! Porque nos força a repensar e a reelaborar! Na Columbia, a minha orientadora era a Joan Vincent, uma inglesa com um background em história, ciência política e antropologia e que, como os meus professores de sociologia da USP, estava tentando unir Max e Weber. Eu logo me interessei pela antropologia da política. Como vivíamos numa ditadura militar no Brasil, quis entender por que e como o golpe foi aceito tão facilmente ao nível local. Naquela época, a leitura de Os donos do poder, ${ }^{3}$ do Raymundo Faoro, me influenciou. No livro, Faoro cita um coronel da República que diz "o governo mudou, eu estou com o governo". Talvez, ingenuamente, eu quis entender esse aforisma a partir da mudança do populismo para o autoritarismo. Mas, de fato, a tese reconstrói cem anos da história social de um município da Grande São Paulo, cujos primeiros 80 anos se assemelhavam a Macondo dos Cem anos de solidão ${ }^{4}$ do Gabriel García Márquez, mas os últimos 20 foram de grande interpenetração com São Paulo, devido à especulação imobiliária. Meu estudo focaliza as carreiras políticas dos chefetes locais: o "coronel” da Primeira República, que era um simples major, ficou no poder, junto com sua "panelinha" por quase 50 anos! Durante o Estado Novo, o novo chefete era o Zé Grileiro que influenciou a política local por outros 40 anos. Através dessas histórias de vida, expus as interconexões entre público e privado, a recorrente

\footnotetext{
3 Ver Faoro (1958).

4 Ver García Márquez (2014).
} 
corrupção e os processos de dominação e de acesso ao poder através das transformações da localidade no contexto do capitalismo global. Trato da política no sentido antropológico: família, parentesco, compadrio, patrão-cliente. Mostro como um lugarejo caipira se tornou um subúrbio de São Paulo, as continuidades e descontinuidades sociais e o papel ativo desempenhado pelos líderes locais nas permanências e transformações. Numa primeira fase, orientei várias dissertações sobre política ao nível local.

Mas dado o meu interesse na intersecção entre antropologia e história, em 1984, decidi fazer um pós-doutorado em história, com o David Montgomery, especialista em história do trabalho do Departamento de História de Yale. A minha ideia inicial era transformar a minha tese num livro. Mas fiquei fascinada com a assim chamada "história do cotidiano", que é muito antropológica, e aproveitei o tempo para ler, estudar. Entrementes, recebi um convite para ocupar a cátedra de Professor Titular em Estudos Portugueses, em um campus da Universidade de Massachusetts, que fica no sudeste de Massachusetts, onde a população da maioria das cidades é historicamente formada por sucessivos contingentes imigrantes de portugueses e seus descendentes, de Portugal continental, dos Açores, da Madeira e de Cabo Verde, ex-colônia de Portugal. A universidade estava à procura de alguém que pudesse envolver docentes e alunos em pesquisas sobre os portugueses da região. Quando me chamaram para uma entrevista, me levaram para conhecer um dos bairros portugueses de New Bedford, conhecida como a cidade baleeira retratada por Melville e também como a "capital dos portugueses na América". Nesse tour, fui apresentada à Casa da Saudade, onde funcionavam uma biblioteca portuguesa, o centro de assistência ao imigrante, cursos de inglês e português, o clube de futebol, etc. Também me levaram para conhecer o cais, onde estavam ancorados e de onde saíam os barcos de pesca portugueses. Essa excursão trouxe à tona lembranças de minha infância e adolescência no Bom Retiro - um bairro judeu de São Paulo. Me deu muita vontade de realizar pesquisa sobre migrantes portugueses e seus descendentes nessa cidade. Pedi uma licença sem remuneração da Unicamp e aceitei o convite. De imediato, o que mais me chamou a atenção foram os símbolos de várias camadas de tempos e espaços portugueses nessa cidade industrial americana. Pareciam fotografias de tempos e espaços já vividos. Lembravam também a casa da minha avó paterna, com fotografias de parentes que nunca conheci e símbolos da vida anteriormente vivida pela família em Kiev, na 
Ucrânia e, depois, em Rovno [Polônia]. Lembravam também a minha própria divisão de vida vivida entre o Brasil e os Estados Unidos. Por isso, fiquei com muita vontade de estudar o significado das representações e práticas de tempos e espaços anteriores à emigração em New Bedford. Foi assim que iniciei meus estudos sobre questões migratórias, centralizando a minha atenção na construção social da saudade, tanto ao nível do eu quanto da nação. Para além de formular um projeto de história oral sobre a imigração portuguesa no sudeste de Massachusetts, iniciei pesquisa de campo sobre a construção social da saudade e suas intersecções com gênero, raça, classe, etnicidade e nacionalismo. Essa pesquisa teve várias fases, inclusive me levou a realizar uma comparação triangular entre os portugueses de New Bedford e São Paulo e os brasileiros de Lisboa. Mas um dos primeiros resultados foi um videodocumentário, intitulado Saudade (1991), ${ }^{5}$ com base no projeto de história oral, que resultou também no meu envolvimento na área de antropologia visual. Na minha volta à Unicamp, formei com outros colegas o Centro de Estudos de Migrações Internacionais (Cemi), onde desenvolvi um programa integrado de pesquisas, intitulado "Identidades: reconfigurações de cultura e política: estudos de caso de movimentos de populações, signos e capitais", financiado pelo Programa de Auxílio aos Centros de Excelência [Pronex, MCT/CNPq 1997-2004]. Dentre outros projetos, continuei a pesquisar New Bedford e, atualmente, estou em fase de redação de uma história social dessa cidade sob a ótica das migrações.

\section{Experiências de "servicos" à comunidade antropológica}

Fui representante da área de antropologia na Capes durante o triênio 2005-2008. Foi um grande desafio, uma experiência muito importante para mim, aprendi muito sobre política científica! A Miriam Grossi, a quem substituí, me estimulou a expandir o número de programas da área. Também, logo percebi que havia uma demanda reprimida e as possibilidades de expansão na era Lula. Por isso, durante a minha gestão, investi na criação de cursos novos. Assim que fui nomeada, decidi ir ao congresso da REA/Abanne [Reunião

5 Versões em inglês e português disponíveis on-line, respectivamente, em https://vimeo.com/8990792 e https://www.youtube.com/watch?v=YFZQy7sfYe4. 
Equatorial de Antropologia e ABA Norte Nordeste], que foi realizado em Manaus em 2005. Para além de iniciar vários contatos, marquei, com antecedência, uma reunião com antropólogos de várias universidades da Amazônia Legal. Tanto a Ufam quanto a Universidade Federal do Acre estavam interessadas em criar novos programas de pós-graduação. A Ufam estava inicialmente interessada em criar um programa em ciências sociais, mas, quando expliquei que tal programa seria localizado na área de sociologia e não de antropologia, mudaram de ideia. O reitor da Ufam, que era um homem de visão, conseguiu recursos no MEC para a contratação de dez doutores em antropologia, contando com a orientação da ABA, então sob a presidência da Miriam Grossi, na realização dos concursos. De meu lado, consegui o apoio da Capes para a elaboração de um programa de mestrado e doutorado induzido. Foi uma grande vitória, pois, naquela época, o único mestrado existente na Amazônia, da UFPA, havia sido encerrado. Também nessa REA, entrei em contato com a Marina Cardoso, professora da UFSCar, a quem sugeri a criação de um mestrado em antropologia, aliás um programa que deu muito certo e que já conta com um doutorado. Também consegui criar um grupo de trabalho, intitulado Povos, Línguas e Culturas da Amazônia Legal, com a participação de colegas especialistas, vários dos quais que inclusive lecionavam em universidades da região - como Alfredo Wagner, Jane Beltrão e Luiza Garnelo -, que resultou num relatório final sobre o "estado das artes" da antropologia cultural/social, arqueologia e antropologia linguista na Amazônia Legal. Além da criação do programa induzido da Ufam, outro resultado desse grupo de trabalho foi a criação do programa de mestrado e doutorado da UFPA, com foco em três dos quatro campos da antropologia. Ainda, percorri o Nordeste, onde havia uma demanda reprimida por cursos de pós-graduação em antropologia. Imagine, em 2005, só havia dois programas em antropologia social na região; um mais antigo, da UFPE [mestrado e doutorado], e um mestrado bem recente na UFRGN, criado na gestão da Miriam Grossi à frente da Capes. O programa de mestrado e doutorado da UFBA só foi criado em 2006. Hoje há sete programas de mestrado e três de doutorado. Ainda viajei para outras regiões do país: onde havia demanda para a criação de programas de antropologia, lá estava eu. No que concerne à avaliação, conseguimos aumentar os prazos para o mestrado e doutorado. Mas devo salientar que a representação na Capes não é um trabalho individual. Há necessidade de apoio da comunidade científica. Também contei com um 
excelente representante-adjunto, o Gustavo Lins Ribeiro, na época professor da UnB, que me ajudou muito com a formulação do Qualis-Livros e QualisRevistas Eletrônicas. Além do mais, também convidei colegas de várias universidades na formação de um pequeno núcleo para o trabalho de avaliação, trabalho que, aliás, eu detestava! Devo destacar que o Antônio Carlos de Souza Lima, presidente da ABA entre 2015-2016, foi minha "mão direita" em questões relacionadas à Amazônia Legal, acompanhando-me em todas as conversações sobre a Amazônia Legal, no âmbito da Capes. Não somente me acompanhou, mas eu passava a palavra para ele falar sobre a Amazônia, já que ele era o especialista, e não eu. Como vocês podem ver, eu não trabalhei sozinha, trabalhei com a comunidade, com colegas que colaboraram comigo! E isso é um grande ganho!

Outro grande desafio foi presidir a $\mathrm{ABA}$, que é uma associação científica que se destaca por sua incessante atuação em prol de ações políticas e sociais dirigidas à defesa de direitos humanos de diferentes segmentos populacionais - sejam eles indígenas, quilombolas, moradores do campo ou das cidades ou ainda migrantes transnacionais, entre outros - e por sua especial atenção às minorias étnicas, raciais e de gênero. Aliás, Desafios Antropológicos foi o cognome dado à nossa plataforma de gestão para o biênio 2011-2012, já que a nossa proposta focalizava os dilemas, desafios e perspectivas que estavam ocorrendo no contexto de processos de expansão e transformação da antropologia no Brasil. Foram vários os desafios e só foi possível confrontá-los porque houve um trabalho colaborativo com os membros da diretoria, conselho diretor, comissões e comitês. Presidir uma associação significa também saber delegar, contar com colegas de várias áreas. Para além das comissões e comitês existentes, criamos a comissão editorial e os comitês Gênero e Sexualidade; Povos Tradicionais, Meio Ambiente e Grandes Projetos; Deficiência e Acessibilidade; Migrações Internacionais [hoje denominado Migrações e Deslocamentos] e uma comissão de comunicações, a única que não funcionou, já que a $\mathrm{ABA}$ precisa de assessoria de comunicação e constatamos que uma comissão não substitui a necessária assessoria. Ainda mudamos o nome da antiga Comissão de Educação para um mais abrangente, Educação, Ciência e Tecnologia, sinalizando a importância de diálogos não só com as ciências humanas, mas também com as hard sciences e a afirmação da antropologia na elaboração das políticas científicas. Criamos ainda um "fórum de desenvolvimento" e ainda focalizamos a 
questão da ética na pesquisa nas ciências sociais, sob a liderança de Luiz Fernando Dias Duarte e Cynthia Sarti, que foram respectivamente vice-presidente e tesoureira da ABA na nossa gestão e que continuaram nessa lide eventualmente conseguindo, no decorrer dos anos, resultados positivos no que concerne ao reconhecimento das especificidades da pesquisa em ciências humanas em relação aos das ciências exatas.

O biênio 2011-2012 foi de trabalho intenso. A questão indígena, devido à construção da hidrelétrica de Belo Monte, se tornou parte do nosso cotidiano. Até criamos uma seção no site da ABA dedicada às notícias sobre essa problemática, que continua sendo atualizada. E, assim que iniciamos a nossa gestão, ante a possibilidade de licenciamento para início das obras dessa hidrelétrica, tivemos a ousadia de realizar, logo após a nossa posse e em menos de três semanas, o evento "Belo Monte e a Questão Indígena", organizado pelo novo comitê Populações Tradicionais, Meio Ambiente e Grandes Projetos, com o apoio da Comissão de Assuntos Indígenas e em parceria com a UnB, Memorial Darcy Ribeiro e Inesc. Convidamos diferentes protagonistas para exporem seus pontos de vista sobre Belo Monte: lideranças indígenas, antropólogos, representantes governamentais, de ONGs e de movimentos sociais das populações tradicionais. $\mathrm{O}$ impacto dos grandes projetos de desenvolvimento na vida cotidiana das populações tradicionais, especialmente Belo Monte, resultou em dois dos e-books publicados em nossa gestão, Belo Monte e a questão indígena,${ }^{6}$ com contribuições de lideranças indígenas, e Desenvolvimento, reconhecimento de direitos e conflitos territoriais, ${ }^{7}$ ambos accessíveis em http://www.portal.abant.org.br/index. php/e-books. Mas, além de Belo Monte, nos confrontamos com o assassinato de um antropólogo que foi vítima de homofobia, remoções urbanas, devido à especulação imobiliária, recorrentes conflitos entre fazendeiros e os Guarani-Kaiowá, resultando em assassinatos de lideranças indígenas, além do recorrente alcoolismo e até suicídios de jovens, etc. Como estudiosa das migrações, comecei a perceber que havia padrões similares entre o que estava acontecendo ao nível das migrações transnacionais e esses diferentes "deslocamentos" - assassinatos, remoções rurais e urbanas, políticas em relação

Organizado por João Pacheco de Oliveira e Clarice Cohn (2014).

Organizado por Andréa Zhouri (2012). 
às favelas e periferias - que exigiam a nossa atenção à frente da $\mathrm{ABA}$, sobretudo em relação às atuais políticas de governança tecnocrata, militarização e securitização da pobreza. Foi assim que comecei a formular uma perspectiva global das migrações e deslocamentos, através da realização de vários simpósios, que se iniciaram com um pós-evento realizado logo após a $28^{\mathrm{a}} \mathrm{RBA}$, intitulado "Deslocamentos, Desigualdades e Direitos Humanos". ${ }^{8}$ Ao mesmo tempo, a questão da internacionalização e nossos diálogos e intercâmbios não só com sociedades científicas do país, mas também com as do exterior principalmente através da WCAA, World Council of Anthropological Associations [Conselho Mundial das Associações Antropológicas, criado no Brasil, no final da presidência de Gustavo Lins Ribeiro à frente da ABA], assim como da IUAES [International Union of Anthropological and Ethnological Sciences, ou União Internacional de Ciências Antropológicas e Etnológicas] foram importantes tanto do ponto de vista acadêmico quanto político, já que em várias instâncias pudemos contar com o apoio dessas associações, em forma de petições, como no caso dos Guarani-Kaiowá e de Belo Monte, durante a nossa gestão. No nível acadêmico, esses diálogos acadêmicos transacionais resultaram também na publicação de livros e dossiês, como Desafios da antropologia brasileira [alguns dos textos publicados em inglês em um dossiê da Vibrant $]^{9}$ por mim organizado e Margens da violência: subsídios ao estudo do problema de violência nos contextos mexicanos e brasileiros, ${ }^{10}$ ambos accessíveis em http://www.portal.abant.org.br/index.php/e-books. E, finalmente, dedicamos também atenção à divulgação científica além-muros acadêmicos, na realização de uma semana de antropologia na cidade de São Paulo, por ocasião da $28^{\mathrm{a}}$ Reunião Brasileira de Antropologia, com eventos em vários museus paulistas. Para mim, presidir a ABA foi uma honra e um grande aprendizado em todos os sentidos! Foi uma etapa importante. Agora, estou concentrando os meus projetos de pesquisa e minha atuação política em questões relacionadas às migrações e deslocamentos, em suma, nos desloca(migra)mentos.

\footnotetext{
8 Nesse sentido, ver, por exemplo, o dossiê "Deslocamentos" (Ciência e Cultura, 2015).

9 Ver Feldman-Bianco (2013).

${ }^{10}$ Organizado por Antônio Carlos de Souza Lima e Virginia García-Acosta (2014).
} 


\section{Referências}

CIÊNCIA E CULTURA. São Paulo, v. 67, n. 2, abr.jun. 2015. Disponível em: $<$ http://cienciaecultura.bvs.br/scielo.php?script=sci_issuetoc\&pid=0009$672520150002 \& \operatorname{lng}=\mathrm{pt \& nrm}=\mathrm{iso}>$. Acesso em: 30 maio 2016.

FAORO, R. Os donos do poder. Porto Alegre: Globo, 1958.

FELDMAN-BIANCO, B. (Org.). Desafios da antropologia brasileira. Brasília: ABA, 2013.

GARCÍA MÁRQUEZ, G. Cem anos de solidão. 85. ed. Rio de Janeiro: Record, 2014.

LIMA, A. C. de S.; GARCÍA-ACOSTA, V. (Org.). Margens da violência: subsídios ao estudo do problema de violência nos contextos mexicanos e brasileiros. Brasília: ABA, 2014.

OLIVEIRA, J. P. de; COHN, C. (Org.). Belo Monte e a questão indígena. Brasília: ABA, 2014.

SAUDADE. Produção: Bela Feldman-Bianco. Direção: Bela Feldman-Bianco, Michael Majoros e Peter O’Neill. Watertown: Documentary Educational Resources, 1991. color. 58 min.

WAGLEY, C. An introduction to Brazil. New York: Columbia University Press, 1963.

ZHOURI, A. (Org.). Desenvolvimento, reconhecimento de direitos e conflitos territoriais. Brasília: ABA, 2012. 